\title{
DEM Analysis on Size Segregation in Feed Bed of Sintering Machine
}

\author{
Masanori NAKANO, ${ }^{1 *}{ }^{(2}$ Tsukasa $\mathrm{ABE}^{, 2}{ }^{2}$ Junya $\mathrm{KANO}^{3)}$ and Kazuya KUNITOMO ${ }^{1)}$ \\ 1) Ironmaking R\&D Lab., Nippon Steel Corporation, 20-1 Shintomi, Futtsu, 293-8511 Japan. \\ 2) Nishi Nippon Works, JFE \\ Steel Corporation, 1 Mizushima-kawasaki-doori, Kurashiki, 721-8511 Japan. \\ 3) Institute of Multidisciplinary Research for \\ Advanced Materials, Tohoku University, 2-1-1 Katahira, Aoba-ku, Sendai, 980-8577 Japan.
}

(Received on January 11, 2012; accepted on April 2, 2012)

\begin{abstract}
Discrete element method (DEM) was applied to charging process in iron ore sintering and vertical size segregation in the feed bed was anlyized, where a particular charactor of sintering feed, plastisity and stikiness, was expressed by adjusting the rolling friction coefficient to fit a result from a preliminary test on sintering feed flowing out of a box. DEM simulations and comparison with plant data gave the following findings:

1) When the rolling coefficient was 4.0, the calculation resembled the experiment in terms of the angle and the spread of feed after resting.

2) The simulation for a charging apparatus recreated vertical size segregation in feed bed in good agreement with plant data.

3) The simulation showed that the size segregation increased with decreasing chute angle, the change of which was explained with the fact that the horizontal velosity of particle at the bottom end of the chute also increased unless the feed made a build-up on the chute.
\end{abstract}

KEY WORDS: agglomeration; charging; DEM; discrete element method; size segregation; sintering.

\section{Introduction}

Japanese integrated steelmakers use sinter as the main ferrous burden for blast furnaces. Sintering plants make it in the process including: admixed in sintering feed, coke is burnt with down draft for driving sintering reaction: iron ore partially fuses with limestone over $1200^{\circ} \mathrm{C}$ and the consequent melt bonds particles to a mass. The down draft also transfers the heat generated in upper layer to lower layer, which allows coke consumption to reduce in the lower layer than in the upper layer.

Charging process of sintering feed, from a surge hopper via a sloping chute into pallets, helps to develop favorable segregation of coke content vertically across the sintering bed. The mechanism is that natural size segregation occurs while the feed flows along the chute and settles on the slope of feed bed. Since the size of coke is smaller than that of ores, the segregation in size results in that in coke content. Here comes an important technical issue of how to intensify the size segregation by modifying the charging process.

Many experimental apploaches have brought fundamenrtal fondings and lead to new charging aparartus: Fukami et al. ${ }^{1)}$ related vertical size segregation to horizontal velocity of feed particles at the bottom end of slopping chute. Inazumi et $a l^{2)}$ showed periodic collapse of slop occuring at higher feed rate disturbed size segregation, and developed a new

\footnotetext{
* Corresponding author: E-mail: nakano.masanori@nsc.co.jp
} DOI: http://dx.doi.org/10.2355/isijinternational.52.1559 charging apparatus that broaden the width of feed flux falling on slop of feed bed to prevent the collapse. Fukuda et $a l^{3)}$ replaced a bar screen for a slopping chute, and succeeded to make a fine layer at the surface of bed; Nakajima et $a l .{ }^{4)}$ modified bar allignment from flat to curved to intensify segregation. Oyama et al. ${ }^{5)}$ found that magnetic force intensified size segragation and equiped magnets in a feeding drum and a chute plate.

Such resarches based on experiments in original scale that consumed time and money. Nakano et al. ${ }^{6}$ surveyed a down-scaled model experiment and concluded that their model reproduced size segregation in satisfactory manner. However, the art has moved in a different way, to discrete element method (DEM).

DEM has been also used for unit processes in iron ore sintering: Ramos et al. ${ }^{7)}$ used it to describe sinter bed shinking during sintering; Soda et al. ${ }^{8)}$ applied it to granulation process. Both of them succeeded to show visual understandings on the phenomena. Moysey et al. ${ }^{9)}$ have shown a DEM simulation similar to this case for pellet pouring onto a packed bed. However, their particles are different from those of sintering feed in size and cohesiveness as discussed later.

We, therefore, aimed to develop a DEM model for charging aparataus of iron ore sintering, forcusing on size segregation in bed. In this papar we will present first a modelling of particles representative for granules of sintering feed suitable for DEM calculation, next simulation results for several cases with changing chute angles, and finally a comparison of the calculation and the plant data obtained from a sinter- 
ing machine with discussion on the effect of chute angle on the size segregation.

\section{Modelling of Particle}

Many books ${ }^{10)}$ have introduced DEM, showing that it simply consists of a set of equation of motion for discrete particles. To excute the method involves a kind of collision model describing the forces due to particle-particle and particle-wall interactions. We followed the Voigt model, which needs to define the following four parameters: friction coefficients, Young's modulus, Poisson's ratio and rolling friction coefficients.

Granules of sintering feed have a complicated structure as shown in Fig. 1. ${ }^{11)}$ Most particles aggregate to be granules consisting of a centered particle $(>2 \mathrm{~mm})$ and adhering fine particles $(<0.5 \mathrm{~mm})$ on it by water; meanwhile some particles of intermediate size $(0.5-2 \mathrm{~mm})$ exist alone. Such structure makes a granule prastic and sticky. Moreover, sintering feed is a mixture of iron ores, limestone and coke such that the granules have variety in density since the ingredients have different densities.

To define the particle parameters suitable for sintering feed, we examined sintering feed for size and density distributions and flow behavior:

\subsection{Size Analysis}

We prepared a bulk of sintering feed by mixing a typical blend of ingredients for sintering with 7 mass $\%$ water, sampled a $300 \mathrm{~g}$ lot of feed from the bulk, sized the sample as wet with $1.0 \mathrm{~mm}, 2.0 \mathrm{~mm}, 4.75 \mathrm{~mm}, 9.5 \mathrm{~mm}$ sieves and then measured the resulting five sprits for size, number and apparent density.

As a result [Fig. 2], the fraction of under $1 \mathrm{~mm}$ and over $5 \mathrm{~mm}$ were negligibly small [Fig. 2(a)]. The log number decreased with increasing size [Fig. 2(b)]. The apparent density increased $2.1 \mathrm{~g} / \mathrm{cm}^{3}$ to $2.5 \mathrm{~g} / \mathrm{cm}^{3}$ as the size increased $1.5 \mathrm{~mm}$ to $7.5 \mathrm{~mm}$ [Fig. 2(c)].

\subsection{Flow Test}

Figure 3 illustrates the experimental procedure to evaluate flow characteristics of sintering feed.

We prepared another $3 \mathrm{~kg}$ typical sintering feed in the same way descreibed in the section 2.1 and charged it to $300 \mathrm{~mm}$ in height into a $200 \mathrm{~mm} \times 200 \mathrm{~mm} \times 400 \mathrm{mmH}$ container with one side free. Pulling up the free side wall, we allowed the feed to flow outside and repose on the graund, and then measured the horizontal angle of the feed slop.

Figures 4(a) and 4(b) show the reposing feed after the

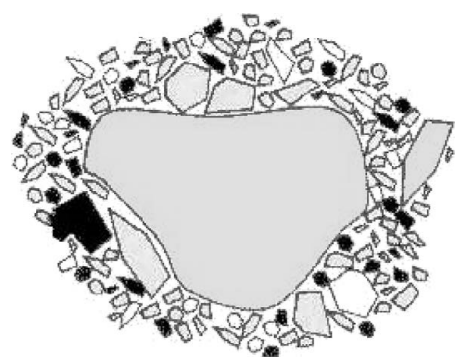

Fig. 1. Schematic diagram of a single granule. flow test. The angle of feed slop was 35 degree.

\subsection{Modelling of Particles}

We arbitaly chose three sizes, 1.5, 3.0, $6.0 \mathrm{~mm}$, for starting DEM modeling, and decided the ratio of their numbers to be $16290,3879,350$ based on the regresion line in Fig. 2(b) and their apparent densities to be $2.09,2.40,2.45 \mathrm{~g} / \mathrm{cm}^{3}$ based on Fig. 2(c), respectively.

There was no reference on mechanical properties of granules. We took commonly-used values of 0.65 for friction coefficient, 2.2 for Young's modulus and 0.3 for Poisson's ratio; ${ }^{8)}$ whereas, we had rolling friction coefficient be a fitting parameter to express gramule's plasticity and stickiness [Table 1].

DEM calculations ran under the same condition as the flow test to decide the rolling friction coefficient, where the model particle sizes were finally enlarged by five times larger than real in the interest of computing time. The simulation, varying the coefficient 1.885 to 16.0 , gave a set of slop angles at which feed rested. When rolling friction coefficient was 4.0, the calculated slop angle met the measured

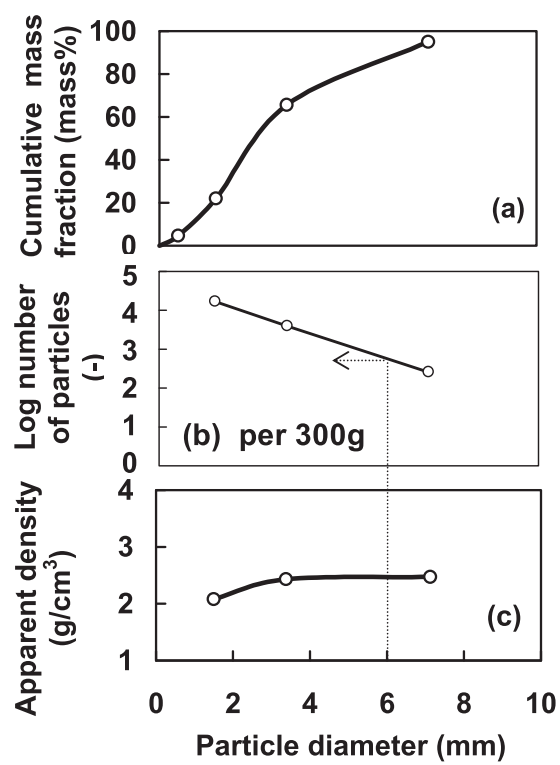

Fig. 2. Attribution of sintering feed granules: (a) Cumulative size distribution, (b) Number of particles and (c) Apparent density of particles; to particle diameter. Mass fraction of $+9.5 \mathrm{~mm}$ fills the short to $100 \%$ at the $7.125 \mathrm{~mm}$ in (a).

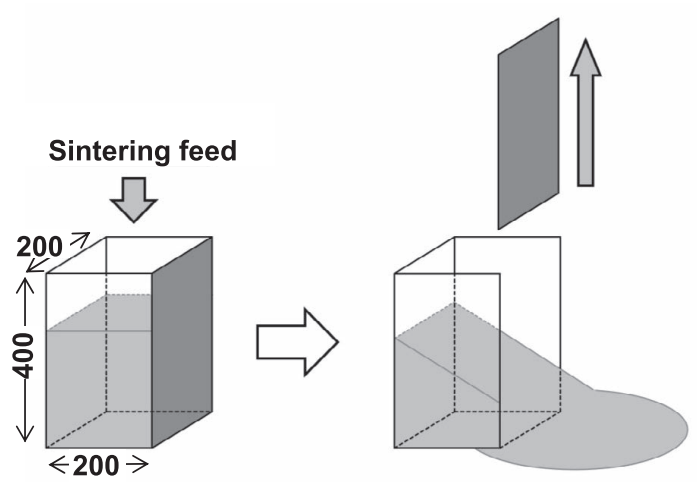

Fig. 3. Experimental procedure for the angle of slop sinter feed rests at. 

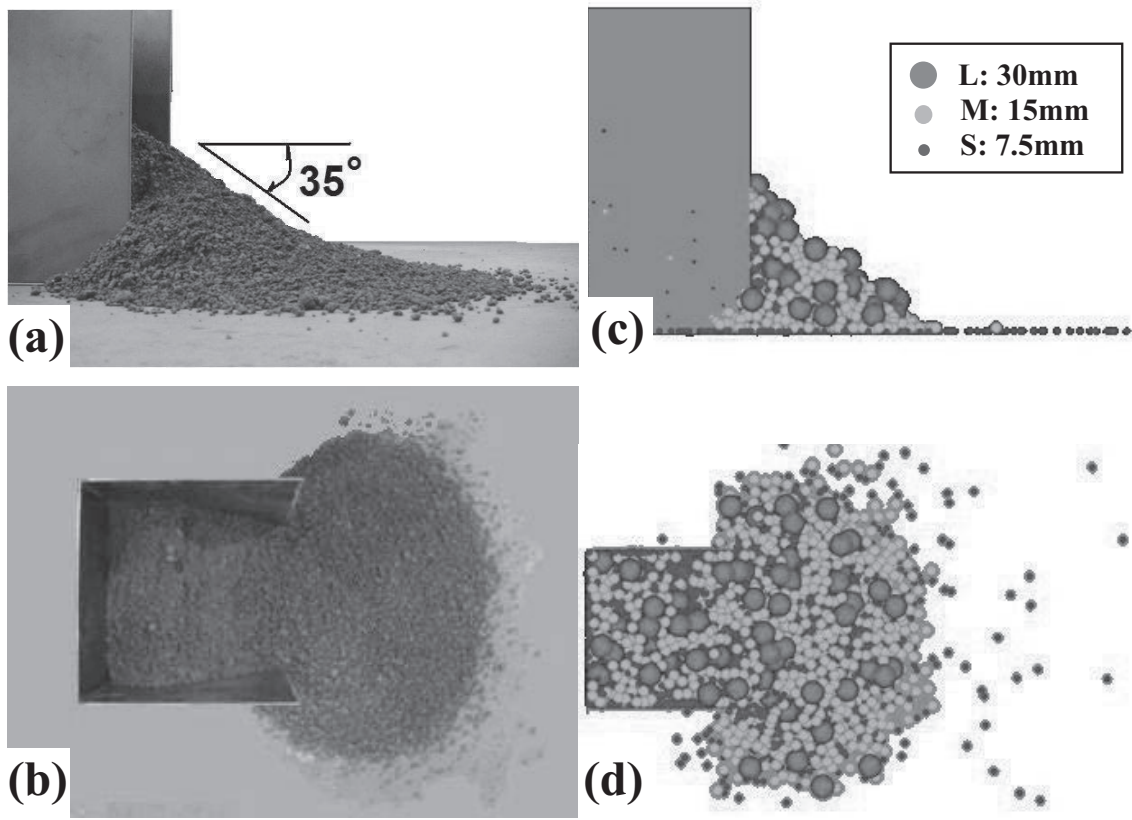

Fig. 4. Comparison of simulation with experiment for the feed rest test. (a) a side view and (b) a top view for experiment; (c) a side view and (d) a top view for calculation.

Table 1. Particle parameter for DEM simulation on the flow test.

\begin{tabular}{lcc}
\hline Diameter of particle & $7.5,15.0,30.0$ & {$[\mathrm{~mm}]$} \\
Number of particle & $9030,2150,194$ & {$[-]$} \\
Density of particle & $2.09,2.40,2.45$ & {$\left[\mathrm{~g} / \mathrm{cm}^{3}\right]$} \\
Friction coefficient (particle-particle) & 0.65 & {$[-]$} \\
Friction coefficient (particle-wall) & 0.65 & {$[-]$} \\
Young's modulus & 2.2 & {$[\mathrm{MPa}]$} \\
Poisson's ratio & 0.3 & {$[-]$} \\
Rolling friction coefficient & $1.885-16.0$ & {$[-]$} \\
\hline
\end{tabular}

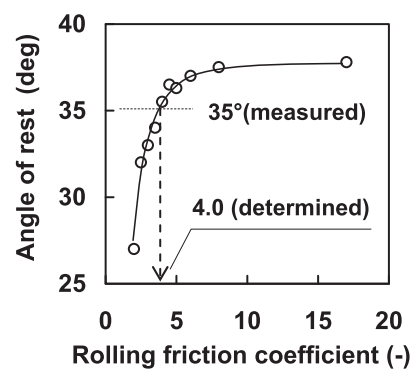

Fig. 5. Change in slop angle of resting feed with rolling friction coefficient by DEM simulation.

one of 35 degree as shown in Fig. 5.

Figures 4(c) and 4(d) show the last snapshot when the rolling friction coefficient is 4.0. The comparison of the DEM and the experiment in Fig. 4 shows the accordance not only in the angle but also the spread of fan shape in the over view and the stops of small particles rolling off, which verifies the parameter set for DEM particles.

\section{Simulation of Charging}

\subsection{Conditions of Calculation}

Figure 6 shows a schematic diagram of the charging

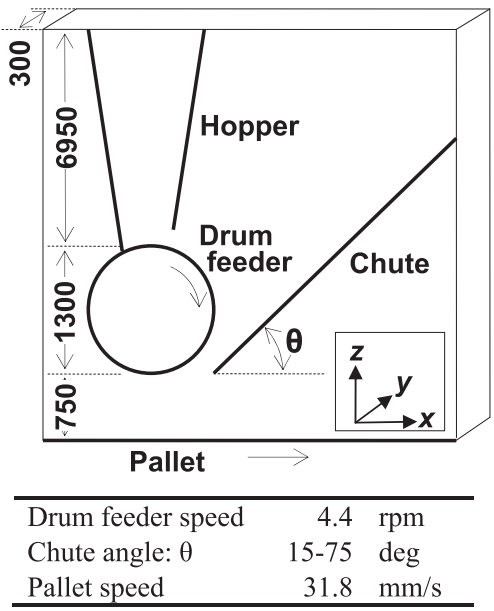

Fig. 6. Schematic diagram of three-dimensional slice model of charging aparatus for DEM.

apparatus employed, whose dimension has based on Kimitsu No. 1 sintering machine, Nippon Steel, except the length of pallet width. That of the plant was $1.3 \mathrm{~m}$; that of the model was reduced to $0.3 \mathrm{~m}$, which accomodated ten pieces of the largest $30 \mathrm{~mm}$ particle at least. The number was said to be enough to avoid so-called wall effect.

Size of particles was the same as used for the flow test, S: $7.5 \mathrm{~mm}, \mathrm{M}: 15 \mathrm{~mm}, \mathrm{~L}: 30 \mathrm{~mm}$; the number of them were $207201,51877,5046$, respectivery. The particles circulated in the system as they warped from the end of pallet to the top of hopper. The model sintering machine operated with a drum feeder at $4.4 \mathrm{rpm}$ and a pallet speed at $31.8 \mathrm{~mm} / \mathrm{sec}$, aiming at $400 \mathrm{~mm}$ in bed height, where the mass flow out of the feeder and that strandwards on the pallet became equal. The employment of larger size and smaller bed height than real were for saving the number of particles for restrected computer memory.

Figure 7 shows the change of time lines of feed bed's shapes. To save computing time every run started with a 


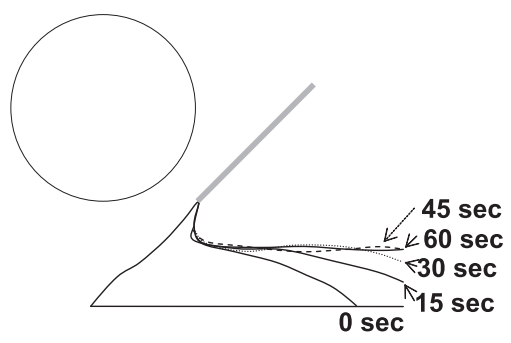

Fig. 7. Time lines of feed bed shapes.

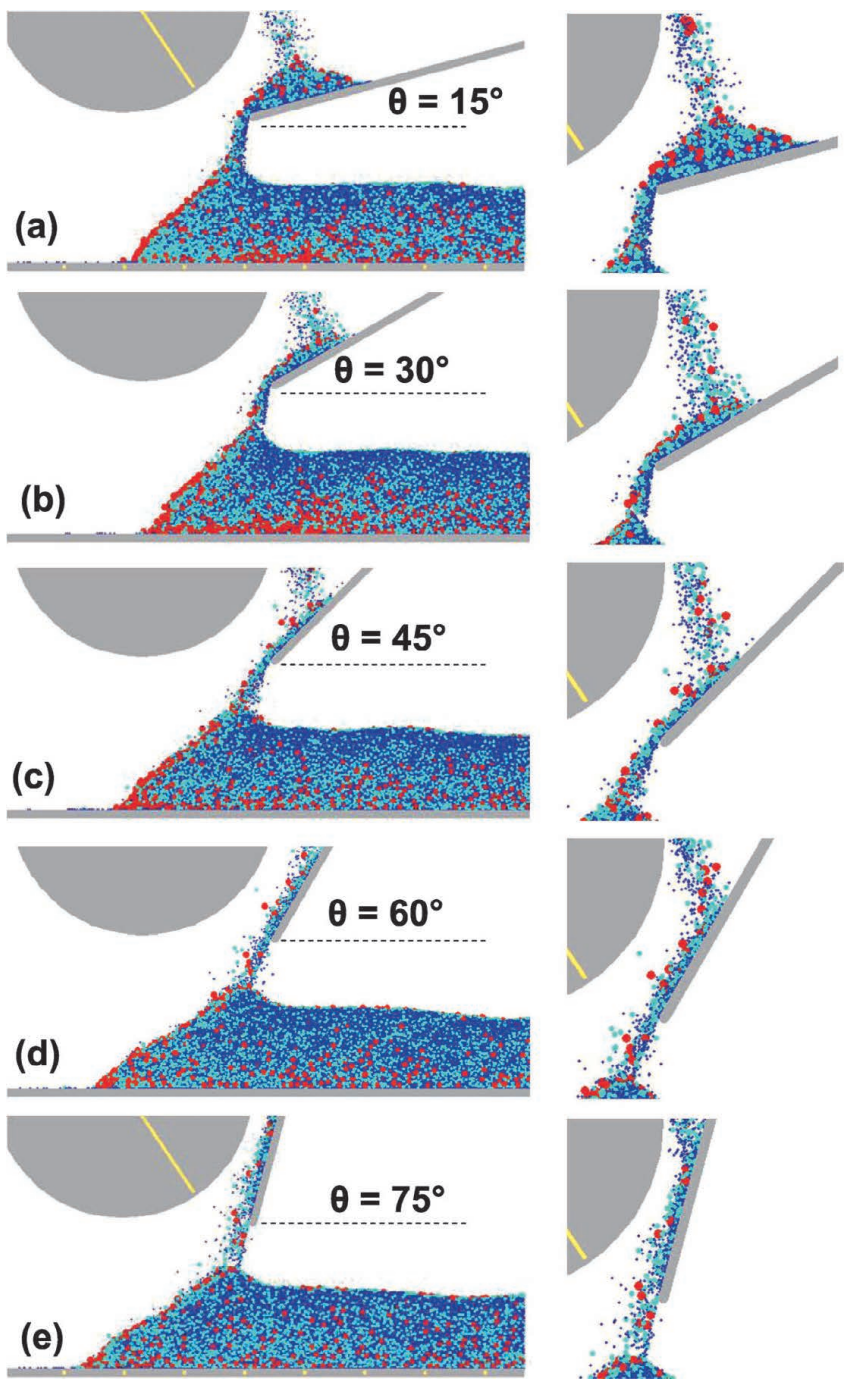

Fig. 8. Snapshots at $60 \mathrm{sec}$ for all chute angles calculated. Figures on right hand side are close-ups around the bottom of chute. S: blue $7.5 \mathrm{~mm}, \mathrm{M}$ : green $15 \mathrm{~mm}, \mathrm{~L}$ : red $30 \mathrm{~mm}$.

same initial condition that some amount of feed was preliminarily piled with a 45 degree chute. The time lines suggested that a steady state condition attained after $45 \mathrm{sec}$; therefore, every calculation terminated at $60 \mathrm{sec}$.

\subsection{Measure and Definition of Segregation}

Figure 9 contains an illustration showing the position at which the magnitude of vertical size segregation was measured. The particles existing from $5 \mathrm{~mm}$ to $600 \mathrm{~mm}$ at $60 \mathrm{sec}$ were counted with separating the $400 \mathrm{~mm}$ bed into 6 layers in the even interval of $66 \mathrm{~mm}$. For each layer a mass-based mean size, $d_{\mathrm{m}}$, was calculated and it was converted to a dimensionless one, $\underline{d}_{\mathrm{m}}$, as $d_{\mathrm{m}} / \mathrm{MS}$ (the total mean size).
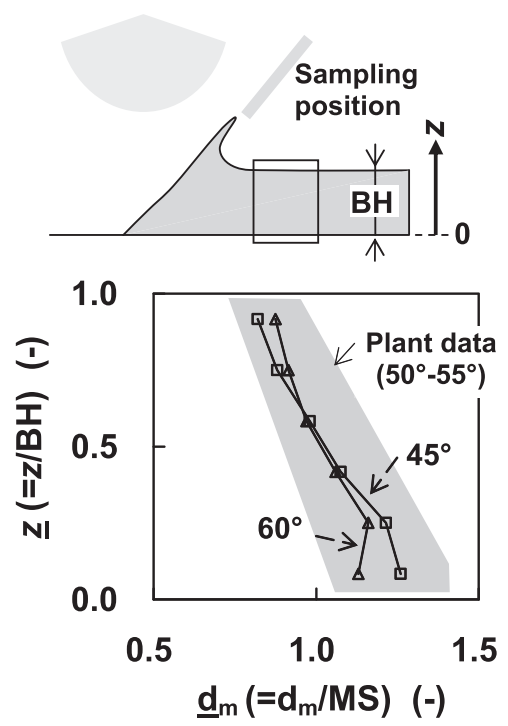

Fig. 9. DEM simulation result and corresponding plant data in term of vertical size segregation in bed.

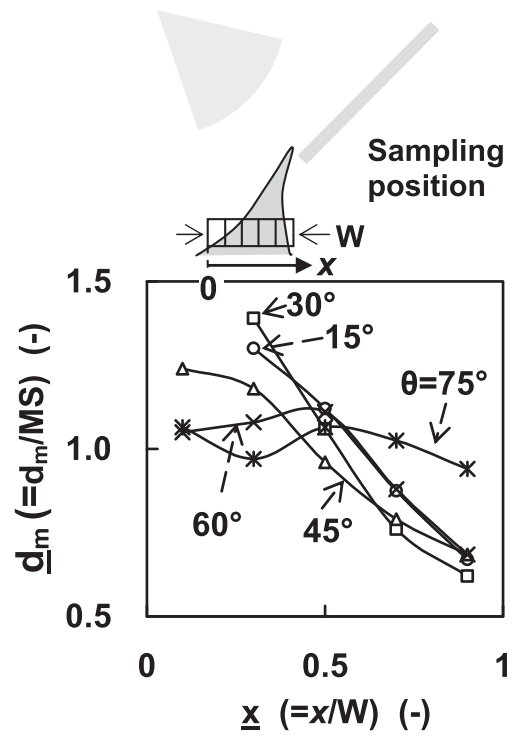

Fig. 10. DEM simulation result in term of horizontal size segregation at the bottom of chute.

Changes in $d_{\mathrm{m}}$ were plotted versus dimensionless bed heights, $\underline{h}$, defined as distances from the bottom, $h$, devided by the total bed height, $\mathrm{BH}(=400 \mathrm{~mm})$. Intensity of size segregation was expressed as the range of $\underline{d}_{\mathrm{m}}, \operatorname{RNG}\left[\underline{d}_{\mathrm{m}}\right](=$ the difference of the maximum and the minimum values of $\underline{d}_{\mathrm{m}}$ ).

Figure 10 includes another illustration showing how to measure size segregation in feed flow at the bottom end of chute, where an imaginary gate consisting of five compartments of $30 \mathrm{~mm}$ in width were placed as aligned its right side just below the bottom of chute. Each compartment counted the particles passing through it from 30 to $60 \mathrm{sec}$ and calculated respective mean size. Similarly to the abovementioned vertical size segregation, dimensionless mean sizes, $\underline{d}_{\mathrm{m}}$, were analyzed with dimensionless positions, $\underline{x}$, defined as distances from the standard point, $x$, devided by the total gate width, $\mathrm{W}(=150 \mathrm{~mm})$.

\subsection{Results and Discussion}

3.3.1. Recreation of Size Segregation by DEM Simulation

Figure 8 shows snapshots at $60 \mathrm{sec}$ with chute angles 
from 15 to 75 degree, where the colors, red, green and blue means their sizes, L, M and S, respectively. Figures on the right hand side are close-ups at the bottom end of chute.

Simulations recreated size segregations across the bed as coarser particles (red) ran further down than others over the slope of a sinter bed and lay at lower position in the sinter bed; on the other hand, finer particles (blue) lay at upper position. Moreover, it suggested the segregation already emerged in the feed flow at the bottom end of chute. Such behavior definitely appeared when the chute was at 15 or 30 degree as shown in Figs. 8(a) or 8(b).

Figure 9 compares segregation lines for simulation and plant data, where two calculated lines, which show mean size changes along bed height with the chutes of 45 and 60 degree, lie in a hatched area, which means the range of the original plant data scattering due to sampling deviation and change of operation with chute angles between 5055 degree. The likely segregation line for the plant will exist centrally in the area; meanwhile, the estimated line for simulation at the same chute angle as the plant will be between the two calculated lines of 45 and 60 . As the lines estimated by such consideration for simulation and plant will come close together, the agreement supports the validity of the present DEM modeling at least in terms of size segregation in bed.

Real scaled model experiments would be best to duplicate everything at once. When one modifies a charging apparatus, however, he focuses on the size segregation to intensify as a first priority. Then, the DEM modeling developed here will become a useful tool.

Figure 10 shows strand-ward mean size changes at the space between the bottom of chute and the surface of bed, revealing that some amount of segregation has developed already on the chute. The segregation increases with decreasing chute angle until 30 degree whereas it decreases over it due to feed's build-up on the chute as shown in Fig. $8(\mathrm{a})$.

\subsubsection{Change in Segregation Intensity by Chute Angle}

Figure 11(a) shows the relation of size segregation in bed to chute angle, where the chute angle appears as its cosine on the $\mathrm{x}$-axis. The $\cos \theta$ can represent horizontal velocity of feed particles at the bottom end of slopping chute if dissipasion of kinetic energy due to friction against chute is negligble. Segregation intensity stands as the range of $\underline{d}_{\mathrm{m}}$ as meantioned above. There is a plot added for the right angle of chute, which Nakano et al. ${ }^{6}$ obtained when they made a corn-shaped heap of a sintering feed and measured its repose angle.

Size segregation increases with decreasing chute angle. It agrees with the findings of Fukami et al. ${ }^{1)}$ that the vertical size segregation was proportinal to the horizontal velocity of feed particles. There is a smooth tie line between calculations and the extrapolation to angle zero, which secures the division of the effect into two sub-effects depicted as A and $\mathrm{B}$ in circles in Fig. 11(a):

The effect of circle A derives from percolation phenomena occurring while particles roll down the slop of bed, which horizontal velocity of particles cannot affect. Only the effect of circle B reflects the horizontal velocity of particles.

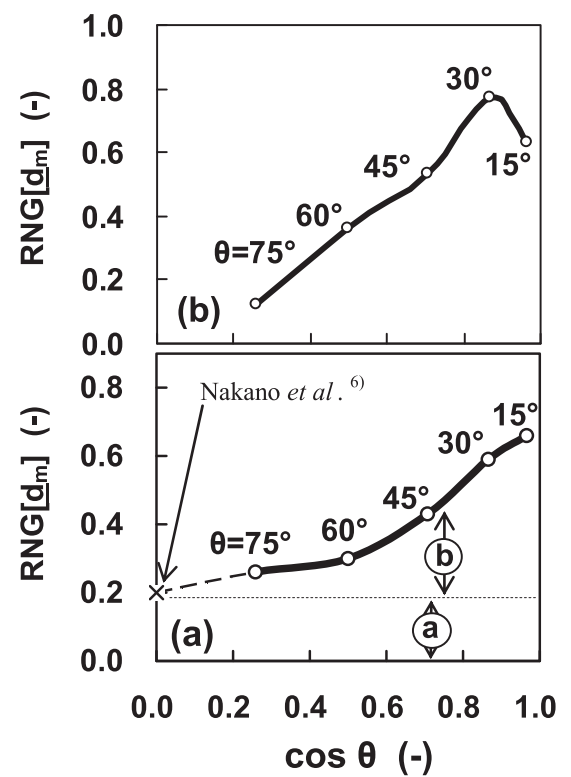

Fig. 11. Changes in size segregation intensities (a) in bed and (b) on chute, expressed as the range of mean sizes with the cosine of chute angle.

Figure 11(b) shows that horizontal size segregation at the bottom end also increases with decreasing chute angle. This is due to the fact that on chute also provides a percolation site as a close examination on Fig. 8 suggests.

The combination of Figs. 11(a) and 11(b) gives an instant interpretation on why changing chute angle affects the size segregation in bed. Since the on-chute segregation increases with $\cos \theta$ in the same manner of the segregation in bed and the magnitudes of intensities are comparable, the effect of circle B seems to come from on-chute segregation.

Such phenomenological explanation is not perfect and fails beyond $\theta=30^{\circ}$. The on-chute segregation takes back beyond $\theta=30^{\circ}$, probably due to the change in the mode of particles rolling on chute as follows: as the close-ups in Fig. 8 show, a build-up emerges on the chute beyond $\theta=30^{\circ}$; before it the particles run against the hard and smooth chute; after it they run on the soft and crumbling build-up. In contrarily, the in-bed segregation still goes up to $\theta=15^{\circ}$ though the rate of change from $30^{\circ}$ to $15^{\circ}$ becomes smaller a little.

The complete understanding of the phenomena is requesting another contribution. Though, it would not be practical because a range of chute angle under the repose angle was out of operation.

\subsubsection{Perspective to Segregation Mechanisms}

Williams $^{12)}$ has reviewed on segregation of particulate materials, classifying the mechanisms that cause segregation into three categories: 1) trajectory segregation, 2) percolation of fine particles and 3) the rise of coarse particles on vibration. It can be easier to understand his classification if the dominant factor is inter-particle distance and it shifts the importance of three possible driving forces, friction against fluid, gravity and inter-particle collision as shown in Table 2. The percolation used to mean the phenomena that smaller particles fall through gaps between larger particles; moreover, he added another mechanism on pouring a heap, a high shear surface layer acts as a screen through which all but largest particles are able to pass. 
Table 2. Three categories of segregation of particulate materials after Williams ${ }^{11)}$ and factors controlling the phenomena.

\begin{tabular}{|c|c|c|c|c|}
\hline & \multirow{2}{*}{$\begin{array}{c}\text { Inter-particle } \\
\text { distance }\end{array}$} & \multicolumn{3}{|c|}{ Diving force } \\
\hline & & Friction & Gravity & Collision \\
\hline 1) Trajectory segregation & Long & Large & $\mathrm{L} / \mathrm{S}$ & Small \\
\hline 2) Percolation of fine particles & Medium & Small & Large & Large \\
\hline $\begin{array}{l}\text { 3) Rise of coarse particles on } \\
\text { vibration }\end{array}$ & Short & Small & Small & Large \\
\hline
\end{tabular}

Charging of sintering machine consists of the flows on an inclined chute and on an inclined surface of bed. The segregation on both flows occurs in the regime of percolation. The conventional mechanism may be dominant on the inclined chute as the relative velocities of particles are small. Variation in chute angle will affect the gravity force to drive the smaller particles falling downwards. On the surface of bed may the later shear layer play an important role as Williams added.

Dolgunin et l. $^{13)}$ have proposed another model for segregation of particles rolling down an inclined chute. They observed a zone having less free volume in the middle depth of flow where larger and denser particles tended to gather, and explained it with an analogy to molecular diffusion of mixed gases. They stated that smaller and lighter particles would get higher velocities than larger and heavier ones after full exchange of momentum due to collision, as a result the fast particles would move to areas having conditions for a long mean free path.

Some of our data indicate reductions in $\underline{d}_{\mathrm{m}}$ itself or in its rate of change at the bottom layer as shown in Fig. 9. This might happen according to Dolgunin model; however, the percolation model also can cover it by shifting the segregation mechanisms as follows: particles get increased in the fraction of largest and they are stopping in the bottom layer, where the shear layer will disappear; smaller's falling mechanism will grow dominant instead.

\section{Conclusions}

DEM approach has visualyzed the charging phenomena of feed in sintering machine, and anlyized vertical size segregation in feed bed, giving the following findings:

(1) The particular charactor of sintering feed, plastisity and stikiness can be expressed by adjusting the rolling friction coefficient to fit a flow test result of sintering feed out of a box. When the coefficient is 4.0, calculation resembles experiment in terms of the angle and the spread of feed after resting.

(2) The simulation for a charging apparatus has recreated vertical size segregation in feed bed in good agreement with plant data. The agreement has verified the modeling employed in this work.

(3) According to the simulation, size segregation increases with decreasing chute angle. Horizontal velosity of particles at the bottom end of the chute explains the change well as far as the chute angle is steap enough to avoid build-up on the chute.

\section{REFFERENCES}

1) K. Fukami, H. Itaya, F. Aratani, K. Nakanishi and H. Nishimura: Tetsu-to-Hagané, 71 (1985), 1888.

2) T. Inazumi, M. Fujimoto, S. Kasama and K. Sato: Tetsu-to-Hagané, 77 (1991), 63.

3) T. Fukuda, M. Himeta, E. Maeshibu, H. Hitoshi, N. Sasaki, M. Sato, T. Nashuno, T. Aso and R. Haga: Tetsu-to-Hagané, 70 (1984), S30.

4) R. Nakajima, M. Hattori, H. Fukuyo, T. Harada, B. Iino, Y. Matsunaga and T. Wada: CAMP-ISIJ, 4 (1991), 116.

5) N. Oyama, K. Igawa, K. Nushiro, M. Ida and N. Fujii: Tetsu-toHagané, 86 (2000), 309.

6) M. Nakano, Y. Hori, S. Nakano, E. Ide, S. Yoshinaga and Y. Hosotani: Tetsu-to-Hagané, 82 (1996), 887.

7) M. V. Ramos, E. Kasai, J. Kano and T. Nakamura: ISIJ Int., 40 (2000), 448.

8) R. Soda, A. Sato, J. Kano, E. Kasai, F. Saito, M. Hara and T. Kawaguchi: ISIJ Int., 49 (2009), 645.

9) P. A. Moysey and M. H. I. Baird: Powder Technol., 196 (2009), 298.

10) Funtai Simyureishon Nyuumon, The Society of Powder Technology, Tokyo, Japan, (1998), 29.

11) Y. Hida, M. Sasaki, T. Enokido, Y. Umezu, T. Iida and S. Uno: Tetsu-to-Hagané, 68 (1982), 400.

12) J. C. Williams: Powder Technol., 15 (1976), 245

13) V. N. Dolgunin, A. N. Kudy and A. A. Ukolov: Powder Technol., 96 (1998), 211. 